\title{
Morphology of Ruthenium Particles for Methanation under Reactive Conditions
}

\author{
Thomas W. Hansen ${ }^{1}$, Federico Masini ${ }^{2}$, Davide Deiana ${ }^{1}$, Jane H. Nielsen ${ }^{2}$ and $\mathrm{Ib}_{\text {Chorkendorff }}{ }^{2}$ \\ 1. Center for Electron Nanoscopy (CEN), Technical University of Denmark, DK-2800 Kgs. Lyngby, \\ Denmark \\ 2. Center for Individual Nanoparticle Functionality (CINF), Department of Physics, Technical University \\ of Denmark, DK-2800 Kgs. Lyngby, Denmark
}

The potential of hydrogen as a future energy carrier is only fully unleashed if fuel processors generating hydrogen of a suitable purity can be engineered. Selective methanation of CO can be used as a first step for cleaning up feed gas for e.g. proton exchange membrane (PEM) fuel cells [1] where CO poisons the platinum electrodes and for removing oxygen containing compounds in hydrogen feeds used in ammonia plants [2].

Ruthenium have been found to effectively catalyze the methanation of carbon monoxide to methane [3]. Joo and co-workers have found that the activity of nanoparticle based catalysts depends heavily and the particle size [4]. A High Pressure Cell/Temperature Programmed Desorption catalytic study showed that the reactivity of $\mathrm{Ru}$ nanoparticles for the methanation reaction decreases as the experiment was repeated. The cause of the loss in activity was found to be annealing causing surface reconstruction which was verified by TPD spectra (Fig. 1). No sintering or significant carbon deposition were detected $[5]$.

In order to further investigate the effect of annealing on particle morphology, size selected ruthenium nanoparticles were prepared using sputtering and aggregation techniques and time of flight mass selection. The samples were studied in an environmental transmission electron microscope (FEI Titan 80-300 ETEM [6]) under both hydrogen and a reactive mixture of $\mathrm{CO}$ and $\mathrm{H}_{2}$.

For ETEM experiments, the size-selected ruthenium nanoparticles were collected on an Echip (Protochips Inc.) coated with a silicon nitride membrane within the cluster source. The sample was first imaged in vacuum at room temperature where the nanoparticles appeared both as multi-domain as well as single crystalline nanoparticles with a jagged surface structure (Fig. 2 left). The sample was then heated to reaction temperature $\left(427^{\circ} \mathrm{C}\right)$ where the jagged surface structure to some extent was lost (Fig. 2 middle). After reaching the reaction temperature, the sample was exposed to a 1:10 mixture of $\mathrm{CO}$ and $\mathrm{H}_{2}$ at $230 \mathrm{~Pa}$ and the sample was again imaged. At this stage, most nanoparticles appeared singlecrystalline like (Fig. 2 right) and the surface had lost the jagged structure compared to the initial state.

This study shows the dynamic nature of catalyst nanoparticles and that, in order to investigate the active state of catalyst samples, they must be imaged under relevant conditions.

\section{References}

[1] P. Panagiotopoulou, D. I. Kondarides, X. E. Verykios, Journal of Physical Chemistry C 115, 12201230 (2011).

[2] I. Chorkendorff, J. W. Niemantsverdriet, Concepts of Modern Catalysis and Kinetics. (Wiley$\mathrm{VCH}, 2003)$.

[3] H.-I. Lee, J. M. White, J. Catal. 63, 261-264 (1980).

[4] S. H. Joo et al., Nano Lett. 10, 2709-2713 (2010). 
[5] F. Masini et al., J. Catal. 308, 282-290 (2013).

[6] T. W. Hansen, J. B. Wagner, R. E. Dunin-Borkowski, Mater. Sci. Technol. 26, 1338-1344 (2010).
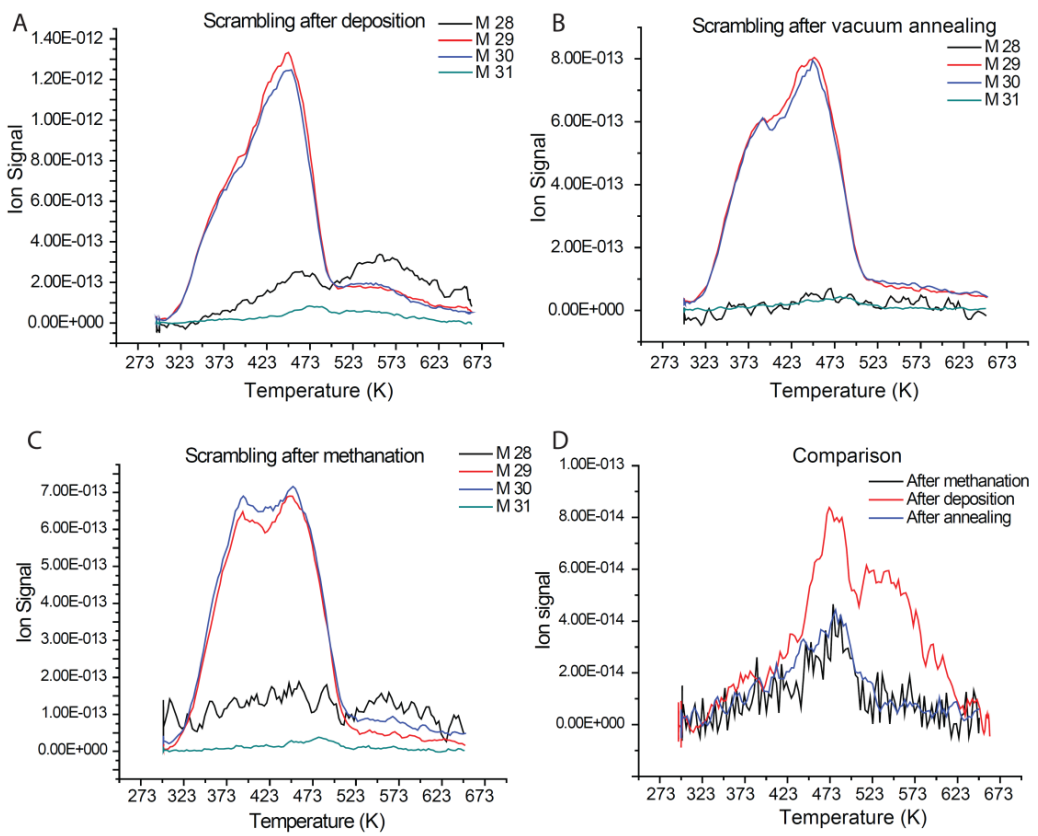

Figure 1. Isotopic CO scrambling TPD spectra after dosing a $1: 1$ mixture of ${ }^{29} \mathrm{CO}$ and ${ }^{30} \mathrm{CO}$ : A) TPD Spectrum collected right after deposition. B) TPD Spectrum collected after sole vacuum annealing. C) TPD Spectrum taken after two methanation runs. D) ${ }^{31} \mathrm{CO}$ traces magnification, comparing ${ }^{31} \mathrm{CO}$ spectra in Figure 1A (red), Figure 1B (blue) and Figure 1C (black). The spectra shown here are for experiments performed on $7 \mathrm{~nm}$ nanoparticles. Adapted from Masini et al. [5].
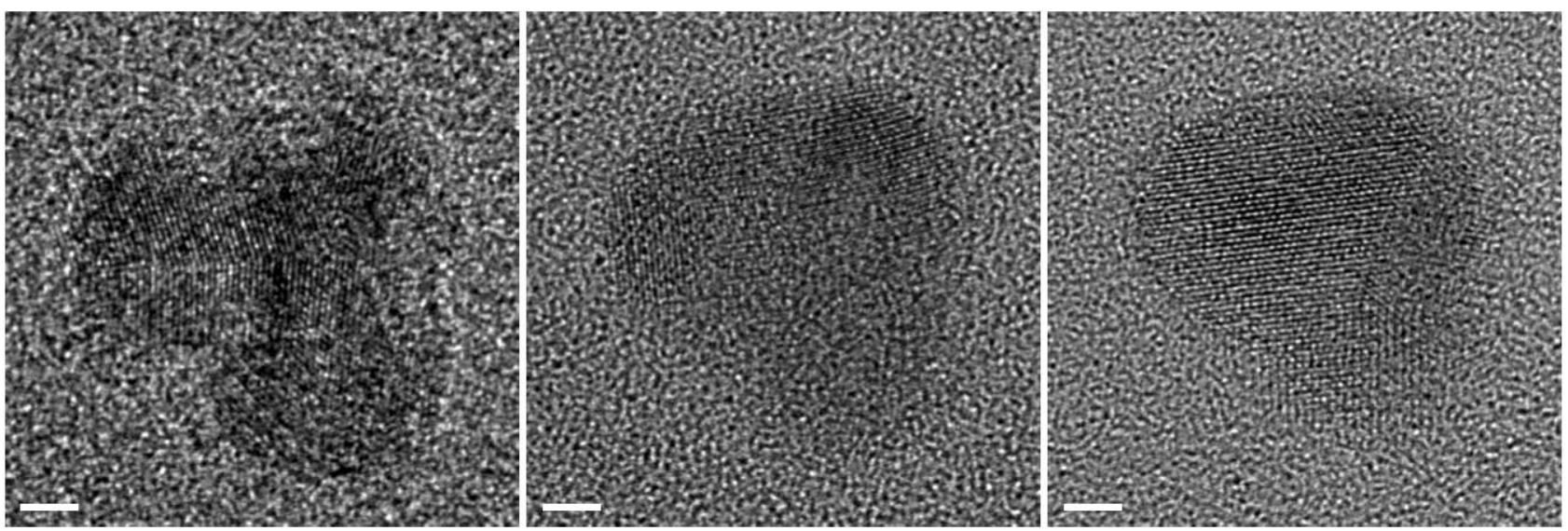

Figure 2. Ruthenium nanoparticle imaged under different conditions relevant for the methanation reaction. Left: Room temperature, vacuum; middle: $427^{\circ} \mathrm{C}$, vacuum; right: $427^{\circ} \mathrm{C} 230 \mathrm{~Pa} 1: 10 \mathrm{CO} / \mathrm{H}_{2}$. 